\title{
Some Physicochemical and Thermal Studies on Organic Analog of a Nonmetal-Nonmetal Monotectic Alloy; 2-Cyanoacetamide-4-chloronitrobenzene System
}

\author{
Manjeet Singh, Rama Nand Rai, Uma Shankar Rai* \\ Department of Chemistry, Centre of Advanced Study, Banaras Hindu University, Varanasi, India \\ E-mail: "usrai_bhu@yahoo.co.in \\ Received June 20, 2011; revised August 3, 2011; accepted August 15, 2011
}

\begin{abstract}
The phase equilibrium data on organic analog of the nonmetal-nonmetal system, involving 2-cyanoacetamide (CA) -4-chloronitrobenzene (CNB), show the formation of a monotectic $(0.10$ mole fraction of $\mathrm{CNB})$ and a eutectic $(0.98$ mole fraction of $\mathrm{CNB})$ with a large miscibility gap starting from 0.10 mole fraction of CNB of monotectic $(\mathrm{M})$ and ending at 0.92 mole fraction of $\mathrm{CNB}$ of monotectic horizontal $\left(\mathrm{M}_{\mathrm{h}}\right)$; the upper consolute temperature $\mathrm{T}_{\mathrm{c}}$ being $63^{\circ} \mathrm{C}$ above the monotectic horizontal at $118^{\circ} \mathrm{C}$ and eutectic temperature is at $85^{\circ} \mathrm{C}$. The values of enthalpy of fusion of the pure components, the eutectic and the monotectic were determined by the differential scanning calorimetry (Mettler DSC-4000 system). Using these data, the size of the critical radius, interfacial energy, excess thermodynamic functions, entropy of fusion, and enthalpy of mixing were calculated. The solid-liquid interfacial energy data confirm the applicability of the Cahn wetting condition. While growth data obey the Hillig-Turnbull equation, the microstructural investigations give typical characteristic features of the eutectic and the monotectic of the system.
\end{abstract}

Keywords: Phase Diagram, Thermal Properties, Eutectic Composite, Monotectic Alloys, Interfacial Energy, Microstructure, Solvent Free Synthesis

\section{Introduction}

It is well known that metal eutectics and intermetallic compounds show their properties entirely different from their parent compounds. The studies on mechanism of solidification behaviour of polyphase alloys, particularly monotectic alloy, are of potential importance for formation of self lubricating alloys and various other industrial applications [1-4]. Although plenty of investigations are in process to get metal eutectics and their intermetallic compounds for different applications, these systems are not suitable for detailed work due to high transformation temperature, difficulties involved in their purification, opacity, limited choice of materials and wide difference in the density of the two components involved [5-8]. Due to low transformation temperature, ease of purification, transparency, wider choice of materials and minimized convection effects on solidification, organic systems are being used as model systems for detailed investigation of the parameters which control the mechanism of solidification which decides the properties of materials. The last two decades have witnessed ample physicochemical investigations on organic materials for non-linear optical and different electronic applications [9-11].

The eutectic reaction is characterized by the isothermal decomposition of liquid eutectic into two solids and the monotectic reaction is associated with the breaking of a monotectic liquid, at the invariant temperature, into a solid and another liquid phase. The eutectic reactions have been examined in detail during the last four decades and their products are currently in wide applications. The freezing behaviour of monotectic is more complicated but interesting [12]. The main problem arises due to a wide freezing range and large density difference between two liquid phases. These results in low cast quality and de-mixing of liquid phases and have delayed the progress and potential use of monotectic as industrial material. A critical scanning of the exiting literature has revealed that the segregation can be influenced and relaxed by vigorous stirring, chill casting and micro-gravity condition.

In general, there are two models which explain the solidification behaviour of monotectic alloys. These are 1) 
diffusion model and 2) wetting model. Although the diffusion model was given by Jackson and Hunt [13] to describe the morphology of regular eutectic, it was successfully applied by different workers [4] to explain the morphology of regular monotectics. According to this modal, during study state eutectic solidification (Figure 1), the $\beta$-phase rejects the atoms of A while the $\alpha$-phase rejects the atoms of $\mathrm{B}$ where $\mathrm{A}$ and $\mathrm{B}$ are the components. These atoms reach the respective interface by diffusion through liquid above the solid. According to the wetting model [14] in the monotectic reaction $\left(\mathrm{L}_{1} \rightleftharpoons \mathrm{S}_{1}+\mathrm{L}_{2}\right)$, the reaction constituents are in contact as given in Figure 2. Chadwick [15] proposed that monotectic composition cannot be grown unless the relative surface energies are such that equilibrium contact between $\mathrm{L}_{2}$ and $\mathrm{S}_{1}$ occurs. Under this condition, Cahn suggested monotectic growth in the light of critical wetting, critical velocity and disjoining pressure. Grugel and Hellawell [16] applied the wetting model for some metallic systems and realized the important of upper consolute temperature $\left(\mathrm{T}_{\mathrm{C}}\right)$, monotectic temperature $\left(\mathrm{T}_{\mathrm{M}}\right)$ and the critical wetting temperature $\left(\mathrm{T}_{\mathrm{W}}\right)$ where $\gamma_{S_{1} L_{2}}=\gamma_{S_{1} L_{1}}+\gamma_{L_{1} L_{2}}$ and suggested balanced wetting. Growth morphology of organic monotectic system was studies by Singh [17] et al., Kaukler and Frazier [18] and Song and Hellawell [19] and they reported strong dependence of monotectic morphology on growth

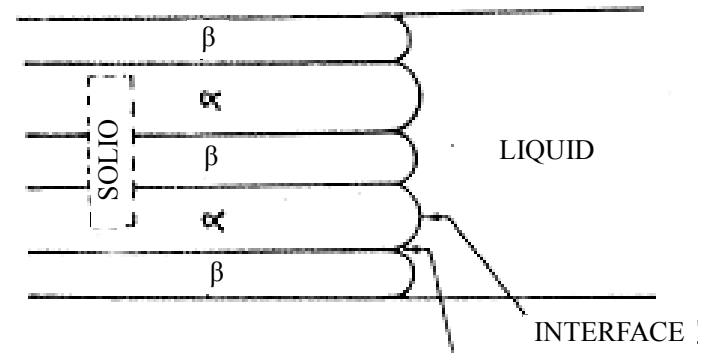

THREE PHASE JOINT

Figure 1. Drawing of the steady state solid-liquid interface morphology.

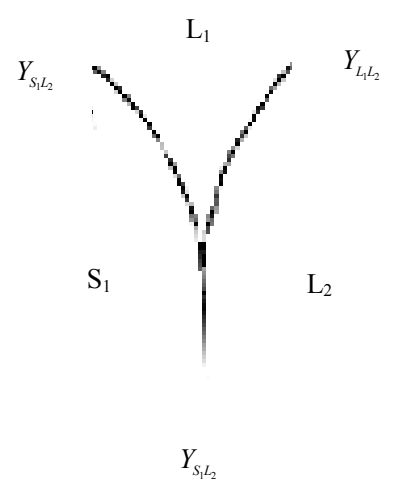

Figure 2. Monotectic reaction components. rate. Kaukler and Frazier reported the dependence of monotectic microstructure on various factors such as relative density of phases, interfacial tension and its variation with temperature and composition, thermal conductivities, fluid dynamic, interface morphology etc. in SCN-Benzene and $\mathrm{SCN}-\mathrm{H}_{2} \mathrm{O}$ monotectic systems. A review on binary phase diagram and microstructure is given by Voort [20] and a survey on the constitution and thermodynamic of monotectic alloys is given by Predel [21]. Application of Jackson-Hunt model of diffusion has been discussed by Majumdar and Chattopadhyay [22] for a metallic system.

The direct observation on solidification of transparent organic systems is the most easy and convenient method to get insight into the mechanism of solidification. It is evident from the available literature on organic monotectic that there are two groups of workers [5,17-19]. One group is involved in the study of phase diagram and morphology of monotectic systems and the effect of various parameters, on it. Today one can observe the solidification process of a transparent model system and generalize the same to metallic systems which produce similar casting patterns. The other group [23-27] is involved in the investigation of phase diagram, growth kinetics and thermochemistry of binary organic monotectics. Neither diffusion model nor wetting model is able to explain all experimental observations satisfactorily. The microgravity can be exploited to understand and control various aspects of materials processing. Shuttle experiment on these systems can through light on wetting behaviour, quality of dispersed in-situ composites, nucleation behaviour in immiscible region, and morphological changes.

Due to several difficulties associated with systems forming monotectics, these alloys have been studies to a very small extent. Nonetheless, some of the articles $[1,26,28,29]$ explain various interesting phenomena of monotectic alloys. As pointed out, the wide freezing range and large density difference between two liquid phases are the main problems. In addition, the role of wetting behaviour, interfacial energy, thermal conductivity and buoyancy during the phase separation process has been a subject of great discussion. In the present investigation, both components, namely, 2-cyanoacetamide $\left(18.97 \mathrm{~kJ} \cdot \mathrm{mol}^{-1}\right)$ and 4-chloronitrobenzene (14.48 $\left.\mathrm{kJ} \cdot \mathrm{mol}^{-1}\right)$ are the material of high enthalpy of fusions and simulate the non-metallic solidification and therefore the present system is a very good example of organic analog of nonmetal-nonmetal system. In the present paper, the details of phase diagram, thermochemistry and linear velocity of crystallization at different undercoolings, heat of fusion, Jackson's roughness parameter, interfacial energy and microstructures are reported. 


\section{Experimental}

\subsection{Materials and Purification}

2-Cyanoacetamide (Aldrich, Germany) was purified by crystallization from de-ionized water while 4-chloronitrobenzene (Aldrich, Germany) was purified by crystallization from ethanol. The melting temperatures of $\mathrm{CA}$ and $\mathrm{CNB}$ were found to be $121.0^{\circ} \mathrm{C}$ and $86.0^{\circ} \mathrm{C}$, respectively, which are consistent to their reported values [30,31].

\subsection{Phase Diagram}

The phase diagram of CA-CNB system was determined by recording the melting point temperature of mixtures and plotting a curve in composition on the $\mathrm{X}$-axis and their respective melting temperature on the Y-axis. In this method [32,33] mixtures of two components covering the entire range of compositions were prepared and taken in test tubes and after sealing the mouth of the test tubes these mixtures were homogenized by repeating the process of melting followed by chilling in ice cooled water 4 times. The melting/complete miscible temperatures of different composition were determined using a melting point apparatus (Toshniwal) attached with a precision thermometer associated with an accuracy of \pm $0.5^{\circ} \mathrm{C}$. During the melting point determination of each composition, the heating rates were kept $2^{\circ} \mathrm{C}-3^{\circ} \mathrm{C} / \mathrm{min}$. However, cooling rate during homogenization was very fast because the test tube containing melts were taken directly into ice cold water.

\subsection{Enthalpy of Fusion}

The heat of fusion of the pure components, the eutectic and the monotectic were determined [34] by differential scanning calorimeter (Mettler DSC-4000 system). Indium and zinc samples were used to calibrate the DSC unit. The amount of test sample and heating rate were about $7 \mathrm{mg}$ and $5^{\circ} \mathrm{C} \mathrm{min}{ }^{-1}$, respectively. The values of enthalpy of fusion are reproducible within $\pm 1.0 \%$.

\subsection{Growth Kinetics}

The growth kinetics of CA, CNB and their eutectic and monotectic were studied $[33,34]$ by measuring the rate of movement of the solid-liquid interface at different undercoolings in a U-shape capillary tube of Jena glass of $150 \mathrm{~mm}$ horizontal portion and $5 \mathrm{~mm}$ internal diameter. Molten samples of pure components, eutectic and monotectic were separately taken in the capillary, and placed in a silicone oil bath. The temperature of the oil bath was maintained using microprocessor temperature controller of accuracy $\pm 0.1^{\circ} \mathrm{C}$. At a particular temperature, below the melting point of the sample, a seed crystal of the same composition was added to start the nucleation and the rate of movement of the solid-liquid interface was measured using a traveling microscope and a stop watch.

\subsection{Microstructure}

Microstructures of the pure components, the eutectic and the monotectic were recorded [32] by placing a drop of molten compound on a hot glass slide. To avoid the inclusion of the impurities from the atmosphere and formation of bubbles, a cover slip was glided over the melt and it was allowed to cool to get a super cooled liquid. In order to facilitate the heterogeneous nucleation, the poly-crystal of the same composition (seed crystal) was added with simultaneous sliding away the slide from the heat source to favor the unidirectional temperature gradient. The unidirectionally solidified sample on glass slide was then placed on the platform of an optical microscope (Leitz Labourlux D). The different regions of the glass slide were viewed and photographs of interesting region were recorded choosing suitable magnification using a camera attached with the microscope.

\section{Results and discussions}

\subsection{Phase Diagram}

The melting points of pure compounds CA and CNB are represented in the extreme left and right side of the diagram at $121^{\circ} \mathrm{C}$ and $86^{\circ} \mathrm{C}$, respectively. The melting point of CA decreases with addition of $\mathrm{CNB}$ up to $\mathrm{M}$ (the monotectic point), after which, even a slight addition of CNB causes the appearance of two immiscible layers (Figure 3). In this figure the immiscibility region is shown by the area $L_{1}+L_{2}$ bounded by the curve $M_{C M}$. The points shown by black circles on the curve represent the complete melting/miscibility temperatures above which the liquids appear as a single homogeneous liquid L. The point $\mathrm{C}$ at the top of the curve is the critical point or consolute point and the corresponding temperature $\left(181^{\circ} \mathrm{C}\right)$ is known as critical solution temperature $\left(\mathrm{T}_{\mathrm{c}}\right)$. The miscibility temperature starts increasing after $\mathrm{M}$, attains its maximum point at $\mathrm{C}$, and thereafter decreases till it attains the monotectic horizontal $\left(\mathrm{M}_{\mathrm{h}}\right)$. The miscibility curve is still continued in the region $\left(\mathrm{S}+\mathrm{L}_{2}\right)$ that lies between the eutectic and monotectic horizontal lines and ends at the point $\mathrm{E}$, the eutectic point. The area $\left(\mathrm{L}_{1}+\mathrm{L}_{2}\right)$ may be regarded as to be made up of an infinite number of tie lines which connect the two liquid phases $\mathrm{L}_{1}$ and $\mathrm{L}_{2}$ at 


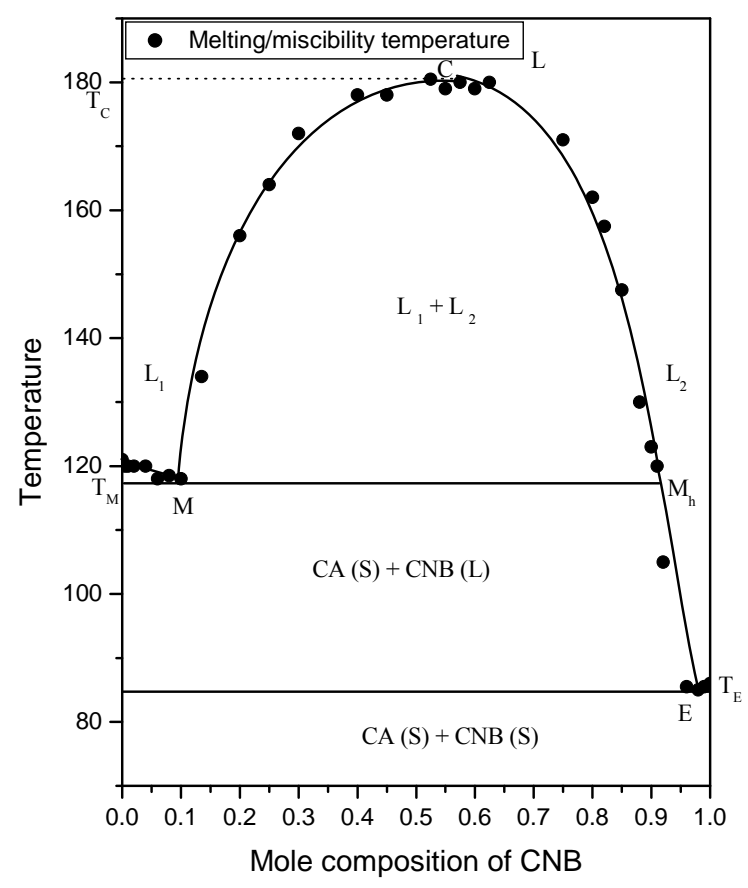

Figure 3. Phase diagram of 2-cyanoacetamide and 4-chloronitrobenzene system.

the extreme sides of the diagram. These tie lines become progressively shorter until the ultimate tie line at the top of the area reduces to a point $\mathrm{C}$ that corresponds to the critical solution temperature. This system involves three types of phase separation processes: 1) $\left.\mathrm{L} \leftrightarrow \mathrm{L}_{1}+\mathrm{L}_{2} ; 2\right) \mathrm{L}_{1}$ $\rightleftharpoons \mathrm{S}_{1}+\mathrm{L}_{2}$;3) $\mathrm{L}_{2} \rightleftharpoons \mathrm{S}_{1}+\mathrm{S}_{2}$. First of these, concerns the phase separation of liquid $\mathrm{L}$ in the two phase region $\left(\mathrm{L}_{1}+\mathrm{L}_{2}\right)$ as the liquid of the composition corresponding $T_{c}$ is cooled below the critical solution temperature. The second reaction is the monotectic phase separation reaction and is similar to the eutectic reaction except that both the phases produced are not solids. This reaction occurs when a liquid of monotectic composition is cooled through the monotectic temperature, $\mathrm{T}_{\mathrm{M}}$. As a result of cooling below $T_{M}$ the liquid $L_{1}$, which is rich in one component (CA) decomposes into a solid phase $\mathrm{S}_{1}$ rich in the first component and another liquid phase $\mathrm{L}_{2}$ rich in the second component (CNB). The third reaction is the eutectic reaction, when a liquid of eutectic composition is cooled below the eutectic temperature $\mathrm{T}_{\mathrm{E}}$, the phase separation reaction results in two solids $S_{1}$ and $S_{2}$.

The phase diagram of the CA-CNB system shows the formation of a monotectic and a eutectic where the mole fractions of CNB are 0.10 and 0.98 , respectively (Figure $3)$. The eutectic and the monotectic melting temperatures correspond to $85.0^{\circ} \mathrm{C}$ and $118.0^{\circ} \mathrm{C}$, respectively. The upper consolute/critical temperature $\left(\mathrm{T}_{\mathrm{c}}\right)$ is $181.0^{\circ} \mathrm{C}$ which is $63.0^{\circ} \mathrm{C}$ above the monotectic horizontal $\left(\mathrm{M}_{\mathrm{h}}\right)$. Above the critical temperature $\left(\mathrm{T}_{\mathrm{c}}\right)$, the two components are miscible in all proportions. However, below $\mathrm{T}_{\mathrm{c}}$ temperature and between 0.10 and 0.98 mole fraction of $\mathrm{CNB}$ compositions range the two immiscible liquids $\left(\mathrm{L}_{1}\right.$ and $\left.\mathrm{L}_{2}\right)$ are produced.

\subsection{Growth Kinetics}

With a view to throw light on the mechanism of solidification, the growth behaviour of the pure components, the eutectic and the monotectic was studies by measuring the linear velocity of crystallization $(v)$ at different undercooling $(\Delta T)$ by observing the rate of movement of moving front in a capillary. The crystallization data are shown in Figure 4 in the form of linear plots which are in accordance with the Hillig-Turnbull equation, [35],

$$
v=u(\Delta T)^{n}
$$

where $\mathrm{u}$ and $\mathrm{n}$ are constants depending on the solidification behaviour of the materials involved. The experimental values of these constants are given in Table 1 . The basic criterion for the growth mechanism [36] is the comparison of the temperature dependence of linear velocity of crystallization with the theoretically predicted, equations. While normal growth generally occurs on the rough interface in which case there is direct proportionality between the crystallization and under cooling, lateral growth is facilitated by the presence of steps, jogs, bends, etc. and under such condition the relationship for the spiral mechanism follows the parabolic law given by

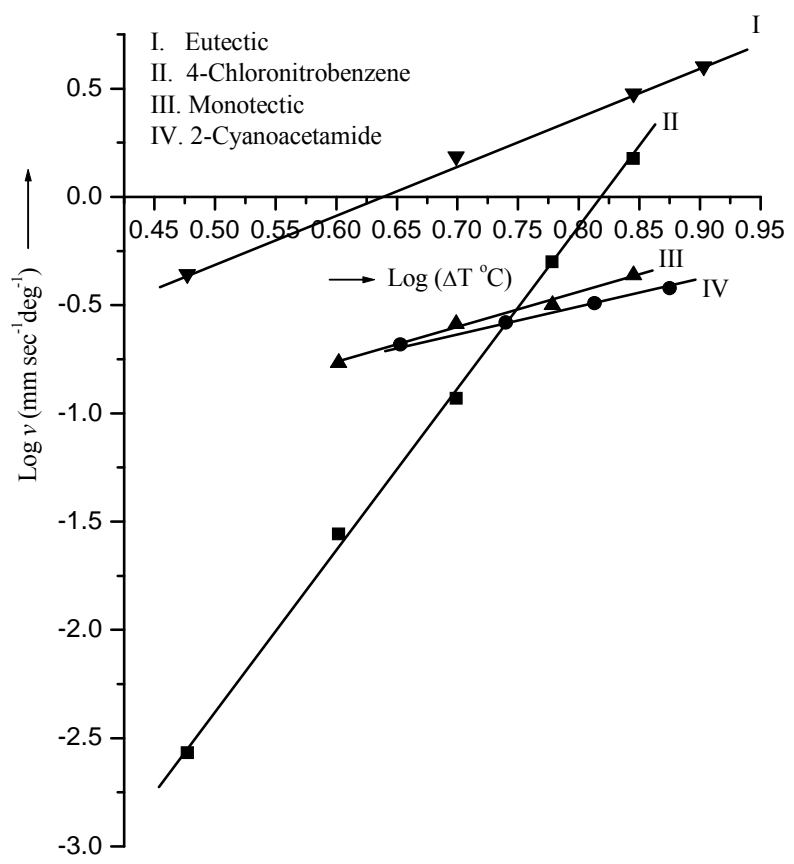

Figure 4. Linear velocity of crystallization at various degree of undercooling for 2-cyanoacetamide and 4-chloronitrobenzene and their monotectic and eutectic. 
Equation (1). While in the case of the eutectic and the monotectic, there is square relationship following parabolic law between linear growth velocity and undercooling, in the case of CA there is direct proportionality between the growth velocity and undercooling. In the case of CNB the growth velocity is very high in comparison to that of CA (Table 1). These findings may be explained by the mechanism given by Winegard et al. [37] where the crystallisation of eutectic/monotectic begins with the formation of the nucleus of one of the phases. This phase grows until the surrounding liquid becomes rich in the other component and a stage is reached when the second component starts nucleating. Now there are two possibilities; either the two initial crystals grow side-by-side or there may be alternate nucleation of the two phases. The deviation of $n$ values from 2 , observed in some cases, is due to difference in temperature of bath and temperature of growing interface. From the values of u (Table 1) it can be concluded that growth velocity of eutectic lies between those of the parent components. However, for monotectic it is higher than one of the parent components. These findings suggest that the two phases of monotectic and eutectic solidify by the sideby-side growth mechanism.

\subsection{Thermochemistry}

The knowledge of enthalpy of fusion values of the pure components, the eutectic and the monotectic are important in understanding the mechanism of solidification, structure of eutectic melt and the nature of interaction between two components forming the eutectic and the monotectic. In addition, different thermodynamic quantities such as entropy of fusion, interfacial energy, enthalpy of mixing, excess thermodynamic functions and Jackson's roughness parameter can be calculated from the entropy of fusion data. The values of enthalpy of fusion of the pure components, the eutectic and the monotectic, determined by the DSC method, are reported in Table 2. For comparison, the value of enthalpy of fusion of the eutectic calculated by the mixture law [14] is also included in the same table. The value of enthalpy of mixing which is the difference of experimental and the

Table 1. Values of $\boldsymbol{n}$ and $\boldsymbol{u}$ for pure components, monotectic and eutectic.

\begin{tabular}{ccc}
\hline Material & $\boldsymbol{n}$ & $\boldsymbol{u}\left(\mathbf{m m} \cdot \mathbf{s e c}^{-1} \cdot \mathbf{d e g}^{-1}\right)$ \\
\hline CA & 1.17 & 0.035 \\
CNB & 7.40 & $8.4 \times 10^{-7}$ \\
Monotectic & 1.61 & 0.018 \\
Eutectic & 2.24 & 0.031 \\
\hline
\end{tabular}

Table 2. Heat of fusion, entropy of fusion and roughness parameter of $\mathrm{CA}, \mathrm{CNB}$ and their monotectic and eutectic.

\begin{tabular}{ccccc}
\hline Materials & $\begin{array}{c}\text { Heat of } \\
\text { fusion } \\
\left(\mathbf{k J} \cdot \mathbf{m o l}^{-\mathbf{1}}\right)\end{array}$ & $\begin{array}{c}\text { Heat of } \\
\mathbf{m i x i n g} \\
\left(\mathbf{k J} \cdot \mathbf{m o l}^{-1}\right)\end{array}$ & $\begin{array}{c}\text { Entropy of } \\
\text { fusion } \\
\left(\mathbf{J} \cdot \mathbf{m o l}^{-1} \cdot \mathbf{K}^{-\mathbf{1}}\right)\end{array}$ & $\begin{array}{c}\text { Roughness } \\
\text { parameter } \\
(\boldsymbol{\alpha})\end{array}$ \\
\hline $\mathrm{CA}$ & 18.97 & & 48.2 & 5.8 \\
$\mathrm{CNB}$ & 14.48 & & 40.3 & 4.9 \\
$\begin{array}{c}\text { Monotectic } \\
\text { (Exp.) }\end{array}$ & 16.48 & & 42.1 & 5.1 \\
$\begin{array}{c}\text { Eutectic } \\
\text { (Exp.) } \\
\text { (Cal.) }\end{array}$ & 13.94 & -0.63 & 38.9 & 4.7 \\
\hline
\end{tabular}

calculated values of the enthalpy of fusion is found to be $-0.63 \mathrm{~kJ} \cdot \mathrm{mol}^{-1}$. As such, three types of structures are suggested [38]; quasi-eutectic for $\Delta_{\text {mix }} H>0$, clustering of molecules for $\Delta_{\text {mix }} H<0$ and molecular solution for $\Delta_{\text {mix }} H=0$. In the present system the negative value of $\Delta_{\text {mix }} H$ for the eutectic suggests the formation of cluster of molecules in the binary melt of the eutectic [39].

The entropy of fusion $\left(\Delta_{\text {fus }} S\right)$ values, for different materials have been calculated by dividing the enthalpy of fusion by their corresponding absolute melting temperatures (Table 2). The value of entropy of fusion of eutectic being less than that of monotectic suggests that entropy is more effective in melting of the monotectic. The entropy of fusion value of eutectic being less than those of components suggest that entropy is more effective in melting of pure components than that of the eutectic. A measure of deviation from ideal behaviour can be best expressed in terms of excess thermodynamic functions, namely, excess free energy $\left(g^{\mathrm{E}}\right)$, excess enthalpy $\left(h^{\mathrm{E}}\right)$, and excess entropy $\left(s^{\mathrm{E}}\right)$ which give a more quantitative idea about the nature of molecular interactions. The excess thermodynamic function $\left(\mathrm{Y}^{\mathrm{E}}\right)$ is defined as the difference between the thermodynamic functions of mixing for a real system and the corresponding values for an ideal system at the same temperature and pressure. Thus,

$$
Y^{E}=\Delta Y_{\text {mix }}(\text { real })-\Delta Y_{\text {mix }}(\text { ideal })
$$

where $\mathrm{Y}$ is any thermodynamic function. The excess thermodynamic functions could be calculated [32,40,41] using the following equations and the values are given in Table 3:

$$
\begin{gathered}
g^{\mathrm{E}}=R T\left[x_{1} \ln \gamma_{1}^{l}+x_{2} \ln \gamma_{2}^{l}\right] \\
h^{\mathrm{E}}=-R T^{2}\left[x_{1} \frac{\partial \ln \gamma_{1}^{l}}{\partial T}+x_{2} \frac{\partial \ln \gamma_{2}^{l}}{\partial T}\right] \\
s^{\mathrm{E}}=-R\left[x_{1} \ln \gamma_{1}^{l}+x_{2} \ln \gamma_{2}^{l}+x_{1} T \frac{\partial \ln \gamma_{1}^{l}}{\partial T}+x_{2} T \frac{\partial \ln \gamma_{2}^{l}}{\partial T}\right]
\end{gathered}
$$

where $\ln \gamma_{i}^{l}, x_{\mathrm{i}}$ and $\frac{\partial \ln \gamma_{i}^{l}}{\partial T}$ are activity coefficient in 
Table 3. Excess thermodynamic functions for the eutectic.

\begin{tabular}{cccc}
\hline Material & $g^{\mathrm{E}}\left(\mathrm{kJ} \cdot \mathrm{mol}^{-1}\right)$ & $h^{\mathrm{E}}\left(\mathrm{k} \cdot \mathrm{J} \cdot \mathrm{mol}^{-1}\right)$ & $s^{\mathrm{E}}\left(\mathrm{J} \cdot \mathrm{mol}^{-1} \cdot \mathrm{K}^{-1}\right)$ \\
\hline CA-CNB eutectic & 0.2176 & 49.527 & 0.1377 \\
\hline
\end{tabular}

liquid state, the mole fraction and variation of log of activity coefficient in liquid state as function of temperature of the component $i$.

It is evident from Equations (3)-(5) that activity coefficient and its variation with temperature are needed to calculate the excess functions. Activity coefficient $\left(\gamma_{i}^{l}\right)$ could be evaluated $[23,32]$ by using the equation,

$$
-\ln \left(x_{i} \gamma_{i}^{l}\right)=\frac{\Delta_{\text {fus }} H_{i}}{R}\left(\frac{1}{T_{\text {fus }}}-\frac{1}{T_{i}}\right)
$$

where $x_{i}, \Delta_{\text {fus }} H_{i}, T_{i}$ and $T_{\text {fus }}$ are mole fraction, enthalpy of fusion, melting temperature of component $\mathrm{i}$ and melting temperature of eutectic, respectively. The variation of activity coefficient with temperature could be calculated by differentiating Equation (6) with respect to temperature,

$$
\frac{\partial \ln \gamma_{i}^{l}}{\partial T}=\frac{\Delta_{\text {fus }} H_{i}}{R T^{2}}-\frac{\partial x_{i}}{x_{i} \partial T}
$$

$\partial x_{i} / \partial T$ in this expression can be evaluated by considering two points around the eutectic. The positive values of excess free energy indicate that the interaction between the like molecules (CA-CA and CNB-CNB) are stronger than the interaction between the unlike (CACNB) molecule [40].

The solid-liquid interfacial tension affects the enthalpy of fusion value and plays an important role in determining the kinetics of phase transformation. When liquid is cooled below its melting temperature, the melt does not solidify spontaneously because under equilibrium condition, it contains number of clusters of molecules of different sizes. As long as the clusters are well below the critical size [41], they cannot grow to form crystals and, therefore, no solid would result. Also during growth, the radius of critical nucleus gets influenced by undercooling as well as the interfacial energy. The interfacial energy $(\sigma)$ is given by

$$
\sigma=\frac{C . \Delta_{\text {fus }} H}{\left(N_{A}\right)^{1 / 3}\left(V_{m}\right)^{2 / 3}}
$$

where $\mathrm{N}_{\mathrm{A}}$ is the Avogadro Number, $V_{\mathrm{m}}$ is the molar volume, and parameter $\mathrm{C}$ lies between 0.30 to 0.35 .

The calculated values of interfacial energy using Equation (8) are given in Table 4. The literature [28,29] during the past two decades is replete with various attempts to understand and explain the process of solidification of monotectic alloys. The role of wetting behaviour in a
Table 4. Interfacial energy of 2-cyanoacetamide and 4chloronitrobenzene and their eutectic and monotectic.

\begin{tabular}{cc}
\hline Parameter & Interfacial energy $\left(\mathbf{e r g s} \cdot \mathbf{c m}^{-1}\right)$ \\
\hline$\sigma_{S L_{2}}(\mathrm{CNB})$ & 27.9735 \\
$\sigma_{S L_{1}}(\mathrm{CA})$ & 51.480 \\
$\sigma_{L_{L_{2}}}(\mathrm{CA}-\mathrm{CNB})$ & 3.5716 \\
$\sigma_{\mathrm{E}}(\mathrm{CA}-\mathrm{CNB})$ & 28.445 \\
\hline
\end{tabular}

phase separation process is of immense importance. In view of this, the applicability of Cahn's wetting condition has been tested in the present case. The values of interfacial energy (Table 4), in present case, show applicability of Cahn wetting condition by satisfying the relation,

$$
\sigma_{\mathrm{SL}_{2}}<\sigma_{\mathrm{SL}_{1}}+\sigma_{\mathrm{L}_{1} \mathrm{~L}_{2}}
$$

where $\sigma$ is the interfacial energy between the faces denoted by the subscripts. The interfacial energy between two liquids, $\sigma_{L_{1} L_{2}}$, has been calculated using the equation [42],

$$
\sigma_{L_{1} L_{2}}=\sigma_{S L_{1}}+\sigma_{S L_{2}}-2 \sqrt{\left(\sigma_{S L_{1}} \sigma_{S L_{2}}\right)}
$$

To calculate the size of critical nucleus $\left(r^{*}\right)$ and the influence of undercooling on it, the following equation was used:

$$
r^{*}=\frac{2 \sigma T_{\text {fus }}}{\Delta_{\text {fus }} H \cdot \Delta T}
$$

where $T_{\text {fus }}, \Delta_{\text {fus }} H$ and $\Delta T$ are melting temperature of eutectic, heat of fusion and degree of undercooling, respectively. The computed values of the size of critical nucleus at different undercoolings using the Equations (8) and (11) are given in Table 5. The size of critical nucleus decreases with increase in undercooling. Thus, high undercooling favors the formation of critical nucleus of smaller size. This may be ascribed to the increase in the amplitude of molecular vibration at higher temperature.

\subsection{Microstructure}

In polyphase materials the microstructure gives information about shape and size of the crystallites, which play a significant role in deciding the mechanical, electrical, magnetic and optical properties of materials. According to Hunt and Jackson [43] the type of growth from a melt depends upon the interface roughness $(\alpha)$ defined by

$$
\alpha=\xi \Delta_{f u s} H / R T
$$

where $\xi$ is a crystallographic factor which is generally equal to or less than one. The values of $\alpha$ are reported in Table 2. If $\alpha>2$ the interface is quite smooth and the 
Table 5. Critical radius of 2-cyanoacetamide and 4-chloronitrobenzene their eutectic and monotectic.

\begin{tabular}{ccccc}
\hline Undercooling & \multicolumn{5}{c}{ Critical radius $\times \mathbf{1 0}^{-\mathbf{8}}(\mathbf{c m})$} \\
\hline$\Delta \mathrm{T}\left({ }^{\circ} \mathrm{C}\right)$ & $\mathrm{CA}$ & $\mathrm{CNB}$ & Monotectic & Eutectic \\
3.0 & & 4.623 & & 4.870 \\
4.0 & & 3.468 & 0.3709 & \\
4.5 & 4.757 & & & \\
5.0 & & 2.774 & 0.2967 & 2.922 \\
5.5 & 3.892 & & & \\
6.0 & & 2.311 & 0.2473 & \\
6.5 & 3.293 & & & \\
7.0 & & 1.981 & 0.2119 & 2.087 \\
7.5 & 2.851 & & & \\
8.0 & & & & \\
\hline
\end{tabular}

crystal develops with a faceted morphology. On the other hand, if $\alpha<2$, the interface is rough and many sites are continuously available and the crystal develops with a non-faceted morphology. In the present system, the values of $\alpha$ being greater than 2 in all the cases suggest that the phases grow with faceted morphology.

\section{Microstructure of Monotectic and Eutectic}

The microstructures of eutectic and monotectic are given in Figures 5(a)-(b), respectively. In general, the optical microphotograph of the eutectic is of lamellar nature $[44,45]$. The discontinued lamellae in the figure are due to miscibility of the solid-liquid interface. The broken lamellar, elongated drops and spherical drops are due to higher thermal gradient in the liquid in front of the solid liquid interface. In general, from the energy consideration, there is tendency to form spheres. If the time of formation of spheres is more than the freezing time, the elongated sphere will be observed. On the other hand if time of formation of sphere is less than the time of freezing, the sphere will be observed. The values of interfacial energy given in Table 4 suggest that the wetting condition can be successfully applied to the present system where $\sigma_{S L_{2}}<\sigma_{S L_{1}}+\sigma_{L_{1} L_{2}}$. While the value of $\sigma_{S L_{2}}$ and $\sigma_{S L_{1}}$ are calculated using Equation (8), the value of $\sigma_{L_{1} L_{2}}$ is calculated using the Equation (10), [32].

The microstructure of monotectic is given in Figure 5(b), where faceted growth has been observed. The minor component of the monotectic has been shown in the major component as thin lines in the microstructure. The study on interfacial energy reveals the applicability of Cahn wetting condition and indicates that both phases are wetting to each other.

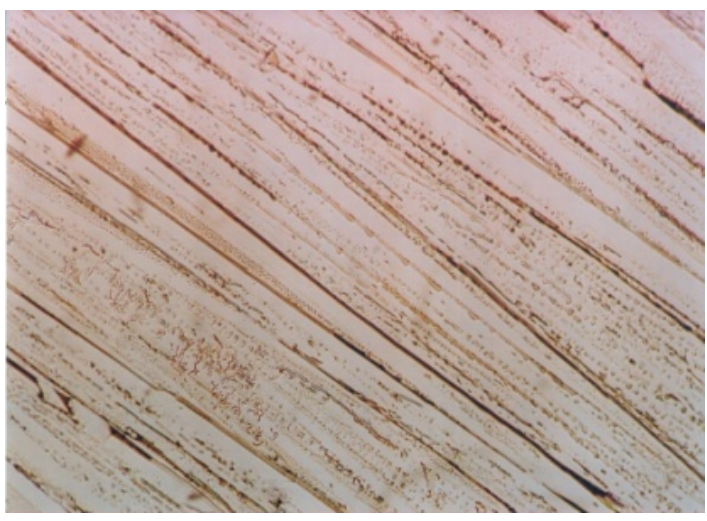

(a)

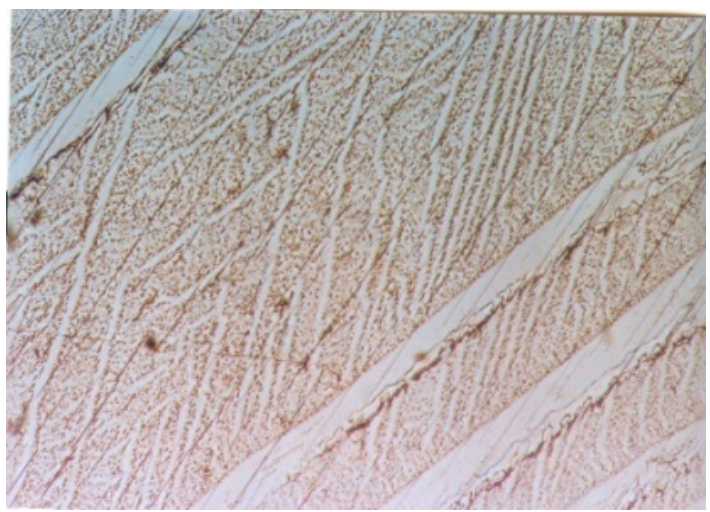

(b)

Figure 5. Directionally solidify optical microphotograph of 2-cyanoacetamide-4-chloronitrobenzene eutectic (a) and monotectic (b).

\section{Conclusions}

The phase diagram between 2-cyanoacetamide and 4-chloronitrobenzene shows the formation of a monotectic and a eutectic with 0.10 and 0.98 mole fractions of $\mathrm{CNB}$, respectively. The diagram shows that the upper consolute temperature is $63^{\circ} \mathrm{C}$ above the monotectic horizontal. The growth kinetics suggests that the growth data obey the Hillig-Turnbull equation for each material, and the size of critical nucleus depends on the undercoolings. The enthalpy of mixing was found to be negative suggesting there by formation of clusters of the materials. The interfacial energies are correlated by the relation $\sigma_{S L_{2}}<\sigma_{S L_{1}}+\sigma_{L_{1} L_{2}}$, which confirms that the Cahn's wetting condition is applicable to the present system. The microstructural investigations show lamellar growth morphology for the eutectic and faceted morphology for the monotectic.

\section{Acknowledgements}

The authors would like to thank the Head, Department of 
Chemistry, B.H.U., Varanasi, for providing the infrastructure facilities.

\section{References}

[1] D. M. Herlach, R. F. Cochrane, I. Egry, H. J. Fecht and A. L. Greer, "Containerless Processing in the Study of Metallic Melts and Their Solidification," International Materials Reviews, Vol. 38, No. 6, 1993, pp. 273-347.

[2] H. Tang, L. C. Wrobel and Z. Fan, "Hydrodynamic Analysis of Binary Immiscible Metallurgical Flow in a Novel Mixing Process: Rheomixing," Applied Physics A: Materials Science \& Processing, Vol. 81, No. 3, 2005, pp. 549-559. doi:10.1007/s00339-004-2638-6

[3] R. Trivedi and W. Kurz, "Dendritic Growth," International Materials Reviews, Vol. 39, No. 2, 1994, pp. 49-74.

[4] B. Majumdar and K. Chattopadhyay, "Aligned Monotectic Growth in Unidirectionally Solidified Zn-Bi Alloys," Metallurgical and Materials Transactions A: Physical Metallurgy and Materials Science, Vol. 31A, No. 7, 2000, pp. 1833-1842. doi:10.1007/s11661-006-0245-1

[5] M. E. Glicksman, N. B. Singh and M. Chopra, "Gravitational Effects in Dendritic Growth," Manufacturing in Space, Vol. 11, 1983, pp. 207-218.

[6] H. Yasuda, I. Ohnaka, Y. Matsunaga and Y. Shiohara, "In-Situ Observation of Peritectic Growth with Faceted Interface," Journal of Crystal Growth, Vol. 158, No. 1-2, 1996, pp. 128-135. doi:10.1016/0022-0248(95)00420-3

[7] K. Pigon and A. Krajewska, "Phase Diagrams in the Binary Systems of 2,4,7-Rinitrofluoren-9-one with Aromatic and Heteroaromatic Compounds. II, Thermodynamic Analysis," Thermochim Acta, Vol. 58, No. 3, 1982, pp. 299-309. doi:10.1016/0040-6031(82)87104-9

[8] S. Akbulut, Y. Ocak, U. Boyiik, K. Keslioglu and N. Marash, "Measurement of Solid-Liquid Interfacial Energy in the Pyrene Succinonitrile Monotectic System," Journal of Physics: Condensed Matter, Vol. 18, No. 37, 2006, pp. 8403-8412. doi:10.1088/0953-8984/18/37/001

[9] J. P. Farges, "Organic Conductors," Marcel Dekker, New York, 1994.

[10] P. Gunter, "Nonlinear Optical Effects and Materials," Springer-Verlag, Berlin, 2000.

[11] N. B. Singh, T. Henningsen, R. H. Hopkins, R. Mazelsky, R. D. Hamacher, E. P. Supertzi, F. K. Hopkins, D. E. Zelmon and O. P. Singh, "Nonlinear Optical Characteristics of Binary Organic System," Journal of Crystal Growth, Vol. 128, No. 1-4, 1993, pp. 976-980. doi:10.1016/S0022-0248(07)80081-9

[12] M. A. Savas, H. Erturan and S. Altintas, "Effects of Squeeze Casting on the Properties of Zn-Bi Monotectic Alloy," Metallurgical and Materials Transactions A: Physical Metallurgy and Materials Science, Vol. 28A, No. 7, 1997, pp. 1509-1515. doi:10.1007/s11661-997-0213-4

[13] K. A. Jackson and J. D. Hunt, "Lamellar and Rod Eutectic Growth," Transactions of the Metallurgical Society of AIME, Vol. 236, 1966, pp. 1129-1142.
[14] J. W. Cahn, "Monotectic Composite Growth," Metallurgical Transactions A: Physical Metallurgy and Materials Science, Vol. 10A, No. 1, 1979, pp. 119-121. doi:10.1007/BF02686415

[15] G. A. Chadwick, "Mettalography of Phase Transformation," Butterworths, London, 1972.

[16] R. N. Grugel and A. Hellawell, "Alloy Solidification in Systems Containing a Liquid Miscibility Gap," Metallurgical Transactions A: Physical Metallurgy and Materials Science, Vol. 12, No. 4, 1981, pp. 669-681. doi:10.1007/BF02649742

[17] N. B. Singh, U. S. Rai and O. P. Singh, "Chemistry of Eutectic and Monotectic; Phenanthrene-Succinonitrile System," Journal of Crystal Growth, Vol. 71, No. 2, 1985, pp. 353-360. doi:10.1016/0022-0248(85)90091-0

[18] W. F. Kaukler and D. O. Frzier, "Crystallization Microstructure in Transparent Monotectic Alloys," Nature (London, United Kingdom), Vol. 323, 1986, pp. 50-52. doi: $10.1038 / 323050 \mathrm{a} 0$

[19] H. Song and A. Hellawell, "The Growth of Tubular or Vermicular Structures in Organic Monotectic Systems," Metallurgical Transactions A: Physical Metallurgy and Materials Science, Vol. 20A, No. 1, 1989, pp. 171-177. doi:10.1007/BF02647504

[20] G. F. V. Voort, "Binary Phase Diagrams and Microstructures," Materials Characterization, Vol. 41, No. 2, 1998, pp. 69-79.

[21] B. Predel, "Constitution and Thermodynamics of Monotectic Alloys-A Survey," Journal of Phase Equilibria, Vol. 18, No. 4, 1997, pp. 327-337.

[22] B. Majumdar and K. Chattopadhyay, "The Rayleigh Instability and the Origin of Rows of Droplets in the Monotectic Microstructure of Zinc-Bismuth Alloys," Metallurgical and Materials Transactions A: Physical Metallurgy and Materials Science, Vol. 27A, No. 7, 1996, pp. 2053-2057. doi:10.1007/BF02651956

[23] P. Gupta, T. Agrawal, S. S. Das and N. B. Singh, "Solvent Free Reactions, Reactions of Nitrophenols in 8-Hydroxyquinoline-Benzoic Acid Eutectic Melt," Journal of Thermal Analysis and Calorimetry, Vol. 104, No. 3, 2011, pp. 1167-1176.

[24] J. W. Rice, J. Fu and E. M. Suuberg, "Anthracene + Pyrene Solid Mixtures: Eutectic and Azeotropic Character," Journal of Chemical \& Engineering Data, Vol. 55, No. 9, 2010, pp. 3598-3605. doi:10.1021/je100208e

[25] C. A. Peters, K. H. Wammer and C. D. Knightes, "Multicomponent NAPL Solidification Thermodynamics," Transport in Porous Media, Vol. 38, No. 1-2, 2000, pp. 57-77. doi:10.1023/A:1006615301396

[26] R. N. Rai, S. R. Mudunuri, R. S. B. Reddi, V. S. A. Kumar Satuluri, S. Ganesamoorthy and P. K. Gupta, "Crystal Growth and Nonlinear Optical Studies of M-Dinitrobenzene Doped Urea," Journal of Crystal Growth, Vol. 321, No. 1, 2011, pp. 72-77. doi:10.1016/j.jcrysgro.2011.02.019

[27] S. Kant, R. S. B. Reddi and R. N. Rai, "Solid-Liquid Equilibrium, Thermal, Crystallization and Microstruc- 
tural Studies of Organic Monotectic Alloy," Fluid Phase Equilibria, Vol. 291, No. 1, 2010, pp. 71-75.

doi:10.1016/j.fluid.2009.12.015

[28] B. Derby and J. J. Favier, "A Criterion for the Determination of Monotectic Structure," Acta Metallurgica, Vol. 31, No. 7, 1983, pp. 1123-1130. doi:10.1016/0001-6160(83)90208-0

[29] A. Ecker, D. O. Frazier and J. I. D. Alexander, "Fluid Flow in Solidifying Monotectic Alloys," Metallurgical Transactions A: Physical Metallurgy and Materials Science, Vol. 20A, No. 11, 1989, pp. 2517-2527. doi:10.1007/BF02666686

[30] J. A. Dean, "Lange's Handbook of Chemistry," McGraw-Hill, New York, 1985.

[31] U. S. Rai and R. N. Rai, "Studies on Physicochemical Properties of the Eutectic and Monotectic in the Urea-P. Chloronitrobenzene System," Journal of Crystal Growth, Vol. 169, No. 3, 1996, pp. 563-569. doi:10.1016/S0022-0248(96)00448-4

[32] S. Chaubey, K. S. Dubey and P. R. Rao, "Aluminum-Cadmium Binary Alloy Phase Diagram," Journal of Alloy Phase Diagram, Vol. 6, 1990, pp. 153-157.

[33] R. N. Rai, "Phase Diagram, Optical, Nonlinear Optical, and Physicochemical Studies of the Organic Monotectic System: Pentachloropyridine-Succinonitrile," Journal of Materials Research, Vol. 99, No. 5, 2004, pp. 1348-1355. doi:10.1557/JMR.2004.0181

[34] U. S. Rai and R. N. Rai, "Physical Chemistry of Organic Eutectics," Journal of Thermal Analysis and Calorimetry, Vol. 53, No. 3, 1998, pp. 883-893. doi:10.1023/A:1010190402954

[35] W. B. Hillig and D. Turnbull, "Theory of Crystal Growth in Undercooled Pure Liquids," Journal of Chemical Physics, Vol. 24, No. 4, 1956, p. 914. doi: $10.1063 / 1.1742646$

[36] D. A. Porter and K. E. Easterling, "Phase Transformation in Metals and Aollys," Vokingham (U. K) co. Ltd.,
Reading, 1982.

[37] W. C. Winegard, S. Majka, B. M. Thall and B. Chalmers, "Eutectic Solidification in Metals," Canadian Journal of Chemistry, Vol. 29, No. 4, 1951, pp. 320-327. doi:10.1139/v51-037

[38] R. N. Rai and U. S. Rai, "Solid-Liquid Equilibrium and Thermochemical Properties of Organic Eutectic in a Monotectic System," Thermochimica Acta, Vol. 363, No. 1-2, 2000, pp. 23-28. doi:10.1016/S0040-6031(00)00625-0

[39] U. S. Rai and R. N. Rai, "Physical Chemistry of the Organic Analog of Metal-Metal Eutectic and Monotectic Alloys," Journal of Crystal Growth, Vol. 191, No. 1-2, 1998, pp. 234-242. doi:10.1016/S0022-0248(98)00105-5

[40] N. Singh, N. B. Singh, U. S. Rai and O. P. Singh, "Structure of Eutectic Melts; Binding Organic Systems," Thermochimica Acta, Vol. 95, No. 1, 1985, pp. 291-293. doi:10.1016/0040-6031(85)80059-9

[41] J. W. Christian, "The Theory of Phase Transformation in Metals and Alloys," Pergamon Press, Oxford, 1965.

[42] R. Good, "Generalization of Theory for Estimation of Interfacial Energies," Industrial \& Engineering Chemistry, Vol. 62, No. 3, 1970, pp. 54-78. doi: $10.1021 /$ ie $50723 \mathrm{a} 009$

[43] J. D. Hunt and K. A. Jackson, "Binary Eutectic Solidification," Transactions of the Metallurgical Society of AIME, Vol. 236, No. 6, 1966, pp. 843-852.

[44] U. S. Rai and P. Panday, "Solidification and Thermal Behaviour of Binary Organic Eutectic and Monotectic; Succinonitrile-Pyrene System," Journal of Crystal Growth, Vol. 249, No. 1-2, 2003, pp. 301-308. doi:10.1016/S0022-0248(02)01906-1

[45] R. N. Rai, U. S. Rai and K. B. R. Varma, "Thermal, Miscibility Gap and Microstructural Studies of Organic Ana$\log$ of Metal-Nonmetal System: P-Dibromobenzene-Succinonitrile," Thermochimica Acta, Vol. 387, No. 2, 2002, pp. 101-107. doi:10.1016/S0040-6031(01)00833-4 